\title{
Cardiac Biomarker Response to Intermittent Exercise Bouts
}

\author{
Authors \\ L. E. Carranza-García ${ }^{1}$, K. George ${ }^{2}$, E. Serrano-Ostáriz ${ }^{3}$, R. Casado-Arroyo ${ }^{4}$, A. L. Caballero-Navarro ${ }^{1}$, \\ A. Legaz-Arrese \\ Affiliations \\ ${ }^{1}$ University of Zaragoza, Section of Physical Education and Sports, Zaragoza, Spain \\ ${ }^{2}$ Liverpool John Moores University, Sport and Exercise Science, Liverpool, United Kingdom \\ ${ }^{3}$ Universidad de Zaragoza, Fisiatría y Enfermería, Zaragoza, Spain \\ ${ }^{4}$ Lozano Blesa Universitary Clinic Hospital, Service of Cardiology, Zaragoza, Spain
}

\section{Key words \\ - soccer \\ weightlifting \\ - cTnT \\ - cTnl \\ - NT-proBNP}

accepted after revision July 20, 2010

Bibliography DOI http://dx.doi.org/ 10.1055/s-0030-1263138 Int J Sports Med 2011; 32: 327-331 (c) Georg Thieme Verlag KG Stuttgart · New York ISSN 0172-4622

Correspondence Dr. Luis Enrique CarranzaGarcía

University of Zaragoza Section of Physical Education and Sports

C/Domingo Miral S/N 50009 Zaragoza

Spain

Tel.: + 34/976/761719

Fax: + 34/976/761720

kique_79@hotmail.com

\section{Abstract}

$\nabla$

The impact of intermittent exercise on cardiac biomarker release has not been clearly established. In experienced athletes, we examined the acute effect of a heavy resistance training session ( $\mathrm{n}=18$ males) and an indoor soccer match ( $\mathrm{n}=21$, 11 males, 10 females) on the release of cTnI, cTnT, and NT-proBNP. Biomarkers were assayed from blood samples collected at rest, immediately post- and at 1, 3, 6, 12, and $24 \mathrm{~h}$ post-exercise. The heavy resistance training session resulted in an increase in NT-proBNP (pre: $15 \pm 17$, peak

\section{Introduction}

$\nabla$

Cardiac-specific biomarkers including troponins (cTnT and cTnI) and $\mathrm{N}$ terminal pro-BNP (NTproBNP), presumed to serologically identify cardiac myocyte damage and dysfunction, are often increased during and after prolonged bouts of endurance exercise in healthy athletes $[11,22,25]$. The factors that promote an increase in cardiac biomarkers during and after prolonged exercise are not well understood. Exercise duration and intensity have been suggested as factors that may promote cardiac biomarker release $[7,19,20,22]$. Despite this, a high percentage of subjects exceeded the upper reference limit (URL) of these cardiac markers after continuous endurance exercise of long $[18,19]$ and short duration $[23]$ as well as after continuous exercise of moderate [20] and very low intensities, such as walking [6]. A plausible explanation for this contradictory evidence has been the limited and varied number of biomarker sampling points employed in past studies. Middleton et al. [12] were the first to assay CTnT repeatedly during and after a laboratory treadmill-based marathon. This paper reported elevated cTnT in all subjects at some point during or post-exercise, albeit with a high post: $41 \pm 56 \mathrm{ng} \mathrm{L}^{-1} ; \mathrm{p}=0.001$ ) but not in cTnI (pre: $0.024 \pm 0.009$, peak post: $0.025 \pm 0.011 \mu \mathrm{g}$ $\mathrm{L}^{-1}, \mathrm{p}=0.809$ ) or cTnT (undetectable in all samples). The indoor soccer match led to an increase in the release of NT-proBNP (pre: $28 \pm 32$, peak post: $66 \pm 56 \mathrm{ng} \mathrm{L}^{-1} ; \mathrm{p}=0.000$ ) and cTnI (pre: $0.026 \pm 0.047$, peak post: $0.033 \pm 0.051 \mu \mathrm{g} \mathrm{L}^{-1}$; $\mathrm{p}=0.008$ ) in both males and females but not cTnT (detectable in only one subject). The current data suggest that intermittent bouts of exercise result in only modest perturbations of cardiac biomarkers with very limited evidence of myocyte injury/insult.

inter-subject variability in cTnT kinetics. These results suggest that multiple samples are necessary to determine the cTn kinetics and a peak concentration.

Whilst many exercise bouts are steady state in nature (from a metabolic and cardiovascular standpoint) other very popular and competitive sports involve intermittent periods of high intensity exertion interspersed with low-intensity recovery periods. Exercise training such as weightlifting has pre-designed work-rest ratios whereas competitive invasion sports such as indoor soccer has a more random and varied pattern of intermittent activity. In both examples there are periods of significant cardiac acceleration and deceleration as well as the potential for substantial changes in parameters such as preload, afterload and contractility. Despite the high levels of participation in intermittent sports the release of cardiac biomarkers associated with such activities is poorly documented. Only 2 studies have evaluated cTn release after intermittent, high intensity team sports $[8,14]$ and the results are contradictory. Only one prior study has assessed cardiac biomarker release after resistance training [24]. The complete lack of 


\begin{tabular}{|c|c|c|c|c|c|c|c|}
\hline & $\begin{array}{l}\text { Age } \\
\text { (yr) }\end{array}$ & $\begin{array}{l}\text { Body mass } \\
(\mathrm{kg})\end{array}$ & $\begin{array}{l}\text { Height } \\
\text { (m) }\end{array}$ & $\begin{array}{l}\text { Training } \\
\text { history (yr) }\end{array}$ & $\begin{array}{l}\text { Training frequency } \\
\text { (sessions week }^{-1} \text { ) }\end{array}$ & Table 1 & Subjects' characteristics. \\
\hline strength training group $(n=18)$ & $24 \pm 3$ & $79.3 \pm 9.4$ & $1.74 \pm 0.06$ & $5 \pm 4$ & $3 \pm 1$ & & \\
\hline male indoor soccer group $(n=12)$ & $24 \pm 4$ & $72.0 \pm 8.7$ & $1.75 \pm 0.06$ & $18 \pm 3$ & $4 \pm 0$ & & \\
\hline female indoor soccer group $(n=12)$ & $22 \pm 4$ & $58.4 \pm 4.3$ & $1.66 \pm 0.04$ & $11 \pm 5$ & $3 \pm 0$ & & \\
\hline
\end{tabular}

detectable cTnT post-exercise may have been limited by the use of a single post-exercise sampling point.

In an attempt to generate new data and also resolve prior contradictory evidence we examined the cardiac biomarkers before and after intermittent exercise bouts by employing multiple sampling points during the $24 \mathrm{~h}$ recovery from exertion. We hypothesised that cTnT, cTnI and NT-proBNP would be increased during the recovery from 2 different bouts of intermittent exercise (indoor soccer and weightlifting).

\section{Materials and Methods}

$\nabla$

\section{Subjects and design}

2 distinct cohorts and studies were completed. Initially, 18 males ( $\bullet$ Table 1), experienced in strength training, (1RM parallel squat: $110 \pm 23 \mathrm{~kg}$; $1 \mathrm{RM}$ bench press: $81 \pm 17 \mathrm{~kg}$ ) gave written informed consent to participate in a single heavy strength training session with serial assessment of cardiac biomarkers during the first $24 \mathrm{~h}$ of recovery. The sample was recruited by invitation to all the rugby teams of the University of Zaragoza. The heavy strength training session lasted $1 \mathrm{~h} 30 \mathrm{~min}$ (18 min of effective exercise). The session consisted of a circuit of 12 exercises that was repeated 3 times (flat barbell bench press, hip sled, lat pulldown, parallel barbell squat, triceps push-down, seated row, leg extension, seated barbell shoulder press, leg curl, barbell biceps curl, bent-knee sit-ups, and lying lower back). All exercises were completed at an intensity of 8-10 RM to muscular failure. A 2minute rest period was consistent between different exercises. The speed of repetitions was standardised at $3 \mathrm{~s}$ per repetition. Prior to exercise, the subjects performed a warm-up (10 min) consisting in the execution of resistance exercises at moderate intensity. The session began at 11.00 a.m.

In a second sub-study 12 male $\left(\mathrm{VO}_{2 \mathrm{max}}: 56.3 \pm 4.0 \mathrm{ml} \mathrm{kg}^{-1} \mathrm{~min}^{-1}\right)$ and 12 female $\left(V_{2 \max }: 47.6 \pm 3.3 \mathrm{ml} \mathrm{kg}^{-1} \mathrm{~min}^{-1}\right)$ indoor soccer players ( $\odot$ Table 1 ) gave written informed consent to participate in an indoor soccer match with the same serial assessment of cardiac biomarkers during recovery. The sample was recruited by invitation to all indoor soccer teams of Zaragoza province competing in national leagues. The match duration was $99 \mathrm{~min}$ for men and $81 \mathrm{~min}$ for women and followed the regulations established by the Fédération Internationale de Football Association (FIFA). For both males and females, the players were assigned to one of the 2 teams according to their usual position. Both teams made a change every $4 \mathrm{~min}$ of actual game time so that that all players participated for the same amount of time (32 of the 40 min constituted actual playing time). The matches began at $11.00 \mathrm{a} . \mathrm{m}$. and took place in an indoor soccer field at a temperature of $18-21^{\circ} \mathrm{C}$ and relative humidity of $50-60 \%$. Prior to exercise, the teams performed the same warm-up that is used in normal competitive matches.

Athletes were advised to avoid strenuous exercise 2 days before the exercise intervention. To exclude acute or chronic diseases, an initial medical examination including recording the history of cardiac symptoms, resting blood pressure, electrocardiography (ECG) and standard echocardiography was performed. At an initial meeting all subjects were familiarised to the study design and measurements. The study was approved by the Research Ethics Committee of the Government of Aragón (Spain) and has been performed in accordance with the ethical standards of the IJSM [10].

\section{Protocols}

For both acute exercise bouts; heart rate (HR) was recorded continuously (Polar, Kempele, Finland) and venous blood samples to measure cardiac biomarkers were taken before, immediately after ( $5 \mathrm{~min}$ ), and $1,3,6,12$, and $24 \mathrm{~h}$ after exercise. For each blood sample, $5 \mathrm{~mL}$ of whole blood sample was drawn from an antecubital vein and collected in serum-gel tubes. Blood samples were left to clot, centrifuged, and the serum drawn off and stored $\left(-80^{\circ} \mathrm{C}\right)$ for subsequent analysis of NT-proBNP and cTnT. NT-proBNP was analysed with an Elecsys proBNP electrochemiluminescent immunoassay on the Roche Elecsys 1010 (Roche Diagnostics, Lewes, United Kingdom), with an analytical range of 5-35000 ng $\mathrm{L}^{-1}$ and intraassay and interassay imprecision of $0.7-1.6 \%$ and $5.3-6.6 \%$, respectively [3]. The URL for NT-proBNP was considered to be $125 \mathrm{ng} \mathrm{L}^{-1}$ [1]. cTnT was analysed using the third-generation TROP T STAT assay by electrochemiluminescent immunoassay technology, used within the Elecsys 1010 automated batch analyser (Roche Diagnostics, Lewes, United Kingdom). Assay imprecision was $5.5 \%$ at $0.32 \mu \mathrm{gL}^{-1}$ and $5.4 \%$ at $6 \mu \mathrm{g} \mathrm{L} \mathrm{L}^{-1}$, with a detection limit of $0.01 \mu \mathrm{g} \mathrm{L}^{-1}$ [4]. Another $5 \mathrm{~mL}$ of whole blood sample was drawn from an antecubital vein and collected into an EDTA plasma tube. The blood was immediately centrifuged, and the plasma was poured off and frozen at $-70^{\circ} \mathrm{C}$ for subsequent analysis of cTnI. cTnI samples were analysed with the Access AccuTnI assay (Beckman Coulter, Fullerton, California). The imprecision profile of 839 duplicate samples showed $10 \%$ and $20 \%$ coefficient of variation values of 0.014 and $0.008 \mathrm{~g} \mathrm{~L} \mathrm{~L}^{-1}$, respectively. The URL for CTnI, defined as the $99^{\text {th }}$ percentile of healthy participants, was $0.04 \mu \mathrm{g} \mathrm{L}^{-1}$ [5].

\section{Statistical analysis}

Statistical analyses were performed using the Statistical Package of Social Sciences (SPSS), version 15.0. Data are expressed as the mean \pm SD unless otherwise stated. To measure the impact of sampling time during recovery on biomarker concentration (pre, immediately post- and at $1,3,6,12$, and $24 \mathrm{~h}$ post-exercise) repeated measures ANOVAs were conducted for all biomarkers. Post-hoc Bonferroni tests were employed where appropriate. Further, the differences between baseline values and a single peak post-exercise value were established for all biomarkers using the repeated measures Students t-test. The association between an increase (difference between baseline and peak post-exercise value) in the cardiac biomarker during recovery and other relevant variables (e.g. baseline biomarker concentration, mean and max exercise HR) were assessed using bivariate Pearson's product moment correlation. For the indoor soccer 
Table 2 Cardiac biomarkers before and after heavy resistance training session.

\begin{tabular}{lllllllll} 
& Pre-exercise & $\mathbf{5}$ min post & $\mathbf{1 h}$ post & $\mathbf{3 h}$ post & $\mathbf{6 h}$ post & $\mathbf{1 2 h}$ post & $\mathbf{2 4 h}$ post & $\boldsymbol{p}$-value \\
$\mathrm{cTnl}$ & $0.024 \pm 0.009$ & $0.012 \pm 0.004^{*}$ & $0.014 \pm 0.008^{*}$ & $0.019 \pm 0.013$ & $0.018 \pm 0.010$ & $0.018 \pm 0.008$ & $0.020 \pm 0.006$ & 0.000 \\
$\left(\mu \mathrm{g} \mathrm{L}^{-1}\right)$ & $(0-0.037)$ & $(0-0.021)$ & $(0-0.032)$ & $(0-0.062)$ & $(0-0.053)$ & $(0-0.029)$ & $(0-0.027)$ & \\
\hline $\mathrm{Nt}-\mathrm{proBNP}$ & $15 \pm 17$ & $19 \pm 21$ & $21 \pm 23$ & $23 \pm 25$ & $21 \pm 22$ & $20 \pm 26$ & $36 \pm 56^{*}$ \\
$\left(\mathrm{ng} \mathrm{L}^{-1}\right)$ & $(5-70)$ & $(5-78)$ & $(5-82)$ & $(5-85)$ & $(5-78)$ & $(5-113)$ & $(5-247)$ & 0.062 \\
\hline
\end{tabular}

* Significant differences with respect to baseline values

The cTnl values decreased in the early phase of recovery, and the NT-proBNP values increased only $24 \mathrm{~h}$ after effort

The URL $\left(0.04 \mu \mathrm{g} \mathrm{L}^{-1}\right)$ for $\mathrm{cTnl}$ was exceeded by one subject at 3 and $6 \mathrm{~h}$ post-exercise and the URL $\left(125 \mathrm{ng} \mathrm{L}^{-1}\right)$ for NT-proBNP was exceeded by a different subject at

$24 \mathrm{~h}$ post-exercise

Table 3 Cardiac biomarkers before and after the male indoor soccer match in male sample.

$\begin{array}{lllllllll} & \text { Pre-exercise } & \mathbf{5} \text { min post } & \mathbf{1 h} \text { post } & \mathbf{3 h} \text { post } & \mathbf{6 h} \text { post } & \mathbf{1 2 h} \text { post } & \mathbf{2 4 h} \text { post } & \boldsymbol{p} \text {-value } \\ \mathrm{cTnl} & 0.038 \pm 0.063 & 0.036 \pm 0.064 & 0.031 \pm 0.053 & 0.037 \pm 0.071 & 0.042 \pm 0.062 & 0.035 \pm 0.064 & 0.033 \pm 0.058 & 0.232 \\ \left(\mu \mathrm{g} \mathrm{L}^{-1}\right) & (0-0.218) & (0-0.219) & (0-0.176) & (0-0.237) & (0-0.206) & (0-0.205) & (0-0.193) & \\ \mathrm{Nt}-\mathrm{proBNP} & 16 \pm 13 & 37 \pm 29^{*} & 33 \pm 25^{*} & 29 \pm 22 & 26 \pm 16 & 23 \pm 9 & 16 \pm 8 & 0.000 \\ \left(\mathrm{ng} \mathrm{L}^{-1}\right) & (5-51) & (5-108) & (5-95) & (5-88) & (5-68) & (5-38) & (5-30) & \end{array}$

* Significant differences with respect to baseline values

The cTnl values did not change significantly, and the NT-proBNP values were increased only in the early phase of recovery

2 subjects exceeded the URL $\left(0.04 \mu \mathrm{gL}^{-1}\right)$ of $\mathrm{cTnl}$ at all sampling points

Table 4 Cardiac biomarkers before and after the female indoor soccer match.

\begin{tabular}{lllllllll} 
& Pre-exercise & $\mathbf{5}$ min post & $\mathbf{1 h}$ post & $\mathbf{3 h}$ post & $\mathbf{6 h}$ post & $\mathbf{1 2 h}$ post & $\mathbf{2 4 h}$ post & $\boldsymbol{p}$-value \\
$\mathrm{cTnl}$ & $0.012 \pm 0.007$ & $0.008 \pm 0.006$ & $0.009 \pm 0.007$ & $0.015 \pm 0.009$ & $0.013 \pm 0.012$ & $0.014 \pm 0.010$ & $0.011 \pm 0.007$ & 0.133 \\
$\left(\mu \mathrm{L} \mathrm{L}^{-1}\right)$ & $(0.003-0.025)$ & $(0.001-0.022)$ & $(0-0.018)$ & $(0.004-0.031)$ & $(0.002-0.036)$ & $(0.002-0.027)$ & $(0-0.021)$ & \\
Nt-proBNP & $42 \pm 42$ & $92 \pm 63^{*}$ & $81 \pm 65^{*}$ & $80 \pm 61^{*}$ & $79 \pm 64^{*}$ & $58 \pm 48$ & $59 \pm 54$ \\
$\left(\mathrm{ng} \mathrm{L}^{-1}\right)$ & $(5-136)$ & $(22-213)$ & $(8-200)$ & $(5-187)$ & $(5-202)$ & $(5-151)$ & $(5-160)$ & 0.000 \\
\hline
\end{tabular}

* Significant differences with respect to baseline values

The cTnl values did not change significantly, and the NT-proBNP values were increased only in the early phase of recovery

2 subjects exceeded the URL ( $125 \mathrm{ng} \mathrm{L}^{-1}$ ) for NT-proBNP at all sampling points

match all analyses were completed on males and females separately as well as with all players combined. The level of significance was set at $\mathrm{p}<0.05$.

\section{Results}

$\checkmark$

All subjects completed all the exercise and blood draws associated with the acute resistance training. In the indoor soccer match one male player was injured and replaced and 2 female players did not complete all of the blood draws. All 3 subjects were excluded from final data analysis.

\section{Heavy resistance training session}

The HR average was $123 \pm 15$ beat. $\mathrm{min}^{-1}$ with a maximum HR of $167 \pm 12$ beat. $\mathrm{min}^{-1}$. A significant effect of sampling time was observed for both cTnI and NT-proBNP but not cTnT, which was undetectable (below $0.01 \mu \mathrm{g} \mathrm{L}^{-1}$ ) in all samples. Post-hoc analysis reported a decrease, from pre-exercise, in cTnI at $5 \mathrm{~min}$ $(\mathrm{p}=0.000)$ and $1 \mathrm{~h}$ post-exercise $(\mathrm{p}=0.002)$ and an increase in NT-proBNP only at $24 \mathrm{~h}$ post-exercise $(\mathrm{p}=0.035)$ ( $(0$ Table 2 ). Somewhat in line with ANOVA data peak post-exercise values for cTnI were not elevated but were raised for NT-proBNP $(15 \pm 17$ vs. $\left.41 \pm 56 \mathrm{ng} \mathrm{L}^{-1}, \mathrm{p}=0.001\right)$. The URL $\left(0.04 \mu \mathrm{L} \mathrm{L}^{-1}\right)$ for $\mathrm{cTnI}$ was exceeded by one subject at 3 and $6 \mathrm{~h}$ post-exercise and the URL (125 $\mathrm{ng} \mathrm{L}^{-1}$ ) for NT-proBNP was exceeded by a different subject at $24 \mathrm{~h}$ post-exercise.

The post-exercise increase in NT-proBNP was associated with the baseline value $(r=0.57, p=0.014)$ but not mean $(r=0.37$, $\mathrm{p}=0.132)$ or maximum $\mathrm{HR}(\mathrm{r}=0.34, \mathrm{p}=0.169)$. There were no significant correlations between changes in cTnI and any other measured variable.

\section{Simulated indoor soccer match}

For both groups (men and women), the mean HR excluding the half-time break time was $159 \pm 20$ beat.min ${ }^{-1}$. The maximum HR was $183 \pm 11$ beat.min ${ }^{-1}$. Although for the outfield players mean HR decreased slightly during the second half (first half: $168 \pm 10$ beat. $\mathrm{min}^{-1}$; second half: $165 \pm 10$ beat. $\mathrm{min}^{-1}, \mathrm{p}=0.019$ ) there were no significant differences in HR response between the male and female participants. HR data for goalies were lower than outfield players in both male and female matches.

There was no significant effect of sampling time upon both cTnI and $\mathrm{cTnT}$ ( which was detectable in only one subject $0.022 \mu \mathrm{g} \mathrm{L}{ }^{-1}$ ) in either males or females (cTnI: $p=0.683$; $c \operatorname{TnT}: p=0.353$ ) ( $\odot$ Tables 3, 4). For the combination of males and females a significant effect of sampling time was observed for NT-proBNP with increases compared to pre-exercise at $5 \mathrm{~min}, 1 \mathrm{~h}, 3 \mathrm{~h}$, and $6 \mathrm{~h}$ post-exercise $(\mathrm{p}=0.000)$. In men, the increase was significant at $5 \mathrm{~min}$ and $1 \mathrm{~h}$ post-exercise ( $\odot$ Table 3 ), and in women, the increase was significant at $5 \mathrm{~min}, 1 \mathrm{~h}, 3 \mathrm{~h}$, and $6 \mathrm{~h}$ post-exercise ( $($ Table 4). Significant differences between pre and peak postexercise values were observed for cTnI $(0.026 \pm 0.047$ vs. $\left.0.033 \pm 0.051 \mu \mathrm{g} \mathrm{L} \mathrm{L}^{-1}, \mathrm{p}=0.008\right)$ and NT-proBNP $(28 \pm 32$ vs. $\left.66 \pm 56 \mathrm{ng} \mathrm{L}^{-1}, \mathrm{p}=0.000\right)$. The increase in cTnI was similar in males $\left(0.009 \pm 0.015 \mu \mathrm{g} \mathrm{L}^{-1}\right)$ and females $\left(0.007 \pm 0.009 \mu \mathrm{g} \mathrm{L}^{-1}\right.$, $\mathrm{p}=0.683$ ). The increase in NT-proBNP was significantly lower in males $\left(22 \pm 17 \mathrm{ng} \mathrm{L}^{-1}\right)$ compared to females $\left(54 \pm 36 \mathrm{ng} \mathrm{L}^{-1}\right.$, 
$\mathrm{p}=0.015$ ) but was largely explained by baseline values (men: $16 \pm 13 \mathrm{ng} \mathrm{L}^{-1}$; women: $42 \pm 42 \mathrm{ng} \mathrm{L}^{-1}$ ). None of these results were substantially modified when the 4 goalies were excluded. 2 male participants exceeded the URL of cTnI at all sampling points and 2 females exceeded the URL for NT-proBNP at all sampling points.

A post-exercise increase in cTnI was weakly associated with mean HR ( $r=0.46, p=0.037)$ and this became non-significant when goalies were excluded from the analysis. In males only, the increase in NT-proBNP was associated with the baseline values $(\mathrm{r}=0.89, \mathrm{p}=0.000)$.

\section{Discussion}

7

The unique findings from the current study of cardiac biomarker response to intermittent bouts of exercise were; a) significant increases in NT-proBNP during the $24 \mathrm{~h}$ of recovery from both soccer and resistance training but few data exceeded the URL, b) a small sex difference in NT-proBNP response to soccer was likely related to higher baseline NT-proBNP in female players, c) changes in cTnI were either absent (resistance training) or modest (soccer) again with few data points exceeding the URL and d) very few detectable levels of cTnT were observed across both studies.

An increase in NT-proBNP concentration after exercise is not surprising when one considers that physiologically and pathologically BNP is elevated in response to volume overload and myocyte stretch [21]. An increase in NT-proBNP has been reported in multiple prolonged endurance exercise studies [16] and the current data extends this to intermittent type exercise. The mean data for NT-proBNP during recovery in the current study are quite low compared to some previous research $[13,18,19]$ and an explanation for this may be the relatively low total exercise volume in intermittent exercise. Although we did not measure distance covered in the indoor soccer players this is likely to be less than $5 \mathrm{~km} \mathrm{[2]} \mathrm{and} \mathrm{the} \mathrm{total} \mathrm{exercise} \mathrm{time} \mathrm{for}$ resistance training was only $18 \mathrm{~min}$. Likewise the total exercise duration was only approximately $90 \mathrm{~min}$ and previous studies have suggested that an exercise-related increase in NT-proBNP is mainly mediated by the duration of activity $[19,20]$.

It is noteworthy that while the peak NT-proBNP after continuous exercise is seen in most cases in athletes during the first $15 \mathrm{~min}$ of recovery $[11,17,25], 72 \%$ of athletes who performed the heavy resistance training session showed a higher level $24 \mathrm{~h}$ post recovery. In fact, the NT-proBNP levels were significantly higher than baseline levels only at $24 \mathrm{~h}$ post-recovery. Future studies should be performed to confirm these results and deduce the differences in the kinetics of NT-proBNP after different types of exertion. Our study also confirms previous results that show that baseline levels are an important factor that determines the increase in NT-proBNP with exercise $[15,20]$. Our study also describes, for the first time, a comparable response in both males and females after adjustment for a higher baseline NT-proBNP in female soccer players. Further research on the exercise-induced increase in NT-proBNP in male and female would be useful especially when total and/or relative work is matched. Irrespective of the statistical significance of the increase in NT-proBNP during recovery from resistance training and indoor soccer play in both males and females the number of individual values over the URL was very small. The increase in NT-proBNP with exercise of mul- tiple types, durations and volumes can likely be viewed as a physiological phenomenon with little or no clinical relevance. Detectable cTnT was only found in one male participant after the indoor soccer intervention. These results confirm the previously established findings through a simple pre-post exercise design after a heavy resistance training session [24] and after intermittent high intensity team sports [8]. The response of cTnI to both exercise bouts was modest even though a statistically significant change was seen after indoor soccer in the comparison of pre and peak post exercise values (no significant ANOVA outcome across all post-exercise time points). The current data is, therefore at odds with a recent study by Nie et al. [14] who reported cTn elevation after a basketball match in adolescent participants. The discrepancy of these results with those observed in this study and in the study of George et al. [8] may be attributed to myocardial immaturity in adolescent players. Interestingly, the mean values of cTnI dropped marginally from baseline during the early recovery period after resistance exercise. It is suggested that this small decrease in cTnI is due to some physiological process because the magnitude of the change was greater than the measurement error. Whether this was due to a haemodilution effect or some other cause altering cTnI clearance is impossible to resolve within the current study. Future research may wish to address this issue. Also, it would be informative to investigate the kinetics of cTnT with newer high sensitive assays. The modest changes in both cTnT and cTnI likely reflect the low total exercise duration and volume compared to many previous endurance and ultra-endurance activities [22]. Previous studies have shown that the increase in CTnI or cTnT is principally mediated by the exercise intensity $[7,22]$ and is also dependent on the exercise duration when the intensity is controlled $[7,20]$. In line with such modest changes the number of samples with cTn concentrations above the URL was low and this further supports the limited clinical impact of exercise-related increases in cTn. The observation of different post-exercise values of cTnI in the indoor soccer intervention, but not in the weight session intervention, may be due to differences in the 2 types of effort with respect to intensity and exercise duration.

Globally, this analysis indicates that intermittent exercise has little impact on circulating levels of cTnI and cTnT. Recent studies employing continuous exercise of high intensity but brief duration (30 min) [23] and long duration but low intensity (walking) [6] as well as bouts with low total volumes of activity [7,20] have reported increases in cTnI and cTnT. Consequently it is possible to postulate that the type of exertion (continuous or intermittent) may be one of the factors that influence the increase in cTn after exercise. This should be studied in a repeated measures design with multiple sampling periods both during and after exercise. Although this interpretation is speculative, the possible differential release of cTnI between continuous and intermittent efforts could be attributed to the short duration of continuous exercise in the intermittent efforts as a consequence of the active and passive recovery phases.

\section{Limitations and future directions}

Whilst both exercise bouts that we employed were intermittent in nature they contained different types of exercise, with different total exercise times, different muscle recruitment and metabolic activity and differences in cardiovascular load. This and the fact that different subject samples were employed in the 2 studies limits the ability to make direct comparisons between the 
bouts. Despite this the absolute differences in cardiac biomarker response were small.

It is also apparent that intermittent exercise is highly variable in terms of exercise parameters (intensities, work-rest ratios, etc.). We employed a "heavy" resistance training intervention, similar to Stephenson et al. [24], in which anaerobic metabolism predominates [9]. The cardiac biomarker response to resistance training sessions with higher aerobic metabolism or circuit training is not known. With respect to the simulated indoor soccer intervention, we evaluated highly trained individuals. Currently, the influence of the training status over the increase in cardiac biomarkers with exercise has not been established through controlled studies.

In conclusion, our results show that a heavy resistance training session and a simulated indoor soccer match using experienced participants induced a small but statistically significant increase in the level of NT-proBNP. Only modest changes in cTnI and cTnT were observed after both exercise bouts. This data, combined with the number of samples about respective URLs, suggest only minor and possibly physiological perturbations to the heart.

\section{Acknowledgments}

We greatly appreciate Dr. Vicente Pej Rodriguez (Grande Covián Medical Center, Zaragoza, Spain), and Drs. Francisco López Alcutan, Miguel Angel Anson Manso (Lozano Blesa Universitary Clinic Hospital, Zaragoza, Spain) for their excellent technical collaboration. Financial support for this study was provided by the Department of Science and Technology, Government of Aragon and Ministry of Science and Innovation of the Spanish Government (DEP 2010-16767).

\section{References}

1 Al-Barjas M, Nair D, Ayrton P, Morris R, Davar J. How can the role of $\mathrm{N}$ terminal pro B Natriuretic Peptide (NT-proBNP) be optimised in heart failure screening? A prospective obsevational comparative study. Eur Heart J Fail 2004; 3: 51 Supplement 1

2 Barbero-Alvarez JC, Soto VM, Barbero-Alvarez V, Granda-Vera J. Match analysis and heart rate of futsal players during competition. J Sports Sci 2008; 26: 63-73

3 Collinson PO, Barnes SC, Gaze DC, Galasko G, Lahiri A, Senior R. Analytical performance of the $\mathrm{N}$ terminal pro $\mathrm{B}$ type natriuretic peptide (NT-proBNP) assay on the Elecsys 1010 and 2010 analysers. Eur J Heart Fail 2004; 6: 365-368

4 Collinson PO, Boa FG, Gaze DC. Measurement of cardiac troponins. Ann Clin Biochem 2001; 38 (Pt 5): 423-449

5 Eggers KM, Lagerqvist B, Venge $P$, Wallentin L, Lindahl B. Persistent cardiac troponin I elevation in stabilized patients after an episode of acute coronary syndrome predicts long-term mortality. Circulation 2007; 116: 1907-1914

6 Eijsvogels T, George K, Shave R, Gaze D, Levine BD, Hopman MT, Thijssen $\mathrm{DH}$. Effect of prolonged walking on cardiac troponin levels. Am J Cardiol 2010; 105: 267-272

7 Fu F, Nie J, Tong TK. Serum cardiac troponin T in adolescent runners: effects of exercise intensity and duration. Int J Sports Med 2009; 30: 168-172
8 George KP, Dawson E, Shave RE, Whyte G, Jones M, Hare E, Gaze D, Collinson $P$. Left ventricular systolic function and diastolic filling after intermittent high intensity team sports. Br J Sports Med 2004; 38: 452-456

9 Gotshalk LA, Loebel CC, Nindl BC, Putukian M, Sebastianelli WJ, Newton $R U$, Häkkinen $K$, Kraemer WJ. Hormonal responses of multiset versus single-set heavy-resistance exercise protocols. Can J Appl Physiol 1997; 22: 244-255

10 Harriss DJ, Atkinson G. International Journal of Sports Medicine - Ethical Standards in Sport and Exercise Science Research. Int J Sports Med 2009; 30: 701-702

11 Herrmann M, Scharhag J, Miclea M, Urhausen A, Herrmann W, Kindermann $W$. Post-race kinetics of cardiac troponin $\mathrm{T}$ and I and $\mathrm{N}$-terminal pro-brain natriuretic peptide in marathon runners. Clin Chem 2003; 49: 831-834

12 Middleton N, George KP, Whyte GP, Gaze D, Collinson P, Shave R. Cardiac Troponin $T$ release is stimulated by endurance exercise in healthy humans. J Am Coll Cardio 2008; 52: 1813-1814

13 Neilan TG, Januzzi JL, Lee-Lewandrowski E, Ton-Nu TT, Yoerger DM, Jassal DS, Lewandrowski KB, Siegel AJ, Marshall JE, Douglas PS, Lawlor D, Picard $M H$, Wood MJ. Myocardial injury and ventricular dysfunction related to training levels among nonelite participants in the Boston marathon. Circulation 2006; 114: 2325-2333

14 Nie J, Tong TK, Shi Q Lin H, Zhao J, Tian Y. Serum cardiac troponin response in adolescents playing basketball. Int J Sports Med 2008; 29: 449-452

15 Sahlén A, Winter R, Lind B, Jacobsen PH, Ståhlberg M, Marklund T, Fux $T$, Svensson J, Braunschweig F. Magnitude, reproducibility, and association with baseline cardiac function of cardiac biomarker release in long-distance runners aged $\geq 55$ years. Am J Cardiol 2008; 102: 218-222

16 Scharhag J, George K, Shave R, Urhausen A, Kindermann W. Exerciseassociated increases in cardiac biomarkers. Med Sci Sports Exerc 2008; 40: 1408-1415

17 Scharhag J, Herrmann M, Urhausen A, Haschke M, Herrmann W, Kindermann $W$. Independent elevations of N-terminal pro-brain natriuretic peptide and cardiac troponins in endurance athletes after prolonged strenuous exercise. Am Heart J 2005; 150: 1128-1134

18 Scott JM, Esch BT, Shave R, Warburton DE, Gaze D, George K. Cardiovascular consequences of completing a $160-\mathrm{km}$ ultramarathon. Med Sci Sports Exerc 2009; 41: 26-34

19 Serrano-Ostáriz E, Legaz-Arrese A, Terreros-Blanco JL, López-Ramón M, Cremades-Arroyos D, Carranza-García LE, Izquierdo-Alvarez S, BocosTerraz $P$. Cardiac biomarkers and exercise duration and intensity during a cycle-touring event. Clin J Sport Med 2009; 19: 293-299

20 Serrano-Ostáriz E, Terreros-Blanco JL, Legaz-Arrese A, George K, Shave $R$, Bocos-Terraz P, Izquierdo-Álvarez S, Bancalero JL, Echavarri JM, Quilez $J$, Aragonés MT, Carranza-García LE. The impact of exercise duration and intensity on the release of cardiac biomarkers. Scand J Med Sci Sports 2009; Nov 17. DOI: 10.1111/j.1600-0838.2009.01042.x

21 Shave R, George K, Gaze D. The influence of exercise upon cardiac biomarkers: A practical guide for clinicians and scientists. Curr Med Chem 2007; 14: 1427-1436

22 Shave R, George KP, Atkinson G, Hart E, Middleton N, Whyte G, Gaze D, Collinson PO. Exercise-induced cardiac troponin T release: a metaanalysis. Med Sci Sports Exerc 2007; 39: 2099-2106

23 Shave R, Ross P, Low D, George K, Gaze D. Cardiac troponin I is released following high-intensity short-duration exercise in healthy humans. Int J Cardiol 2010; 145: 337-339

24 Stephenson C, McCarthy J, Vikelis E, Shave R, Whyte G, Gaze D, George $K$. Effect of weightlifting upon left ventricular function and markers of cardiomyocyte damage. Ergonomics 2005; 48: 1585-1593

25 Vidotto C, Tschan H, Atamaniuk J, Pokan R, Bachl N, Müller MM. Responses of N-terminal pro-brain natriuretic peptide (NT-proBNP) and cardiac troponin I (cTnI) to competitive endurance exercise in recreational athletes. Int J Sports Med 2005; 26: 645-650 